\title{
Medications Prescribed and Occurrence of Falls in General Medicine Inpatients
}

\author{
Richard P Cashin and Meiti Yang
}

\section{ABSTRACT}

Background: Although falls are multifactorial, medications are a key risk factor that may be modifiable. Falls were among the most common occurrences entered into a risk identification system at the authors' hospital.

Objectives: To identify whether general medicine inpatients who had experienced a fall were taking any medications known to be associated with falls.

Methods: The literature was reviewed to develop a list of high-risk medications that have been associated with falls. In a retrospective quality-improvement database-based study, information from the risk identification system was merged with data from the pharmacy dispensing system for general medicine inpatients who had experienced a fall. The primary end point was the percentage of patients with a documented fall who had a prescription for a high-risk medication. The number of such medications that had been prescribed for patients who fell was also calculated.

Results: Eighty-one unique medications were found to be associated with falls. During the study period (April 1, 2008, to March 31, 2009), 151 patients experienced a fall. Of those, 144 (95.4\%) were taking at least one high-risk medication. The mean number of high-risk medications per patient who experienced a fall was 2.2. Of all documented falls, a new high-risk medication had been started within 7 days before the fall for 74 (49.0\%) and within $24 \mathrm{~h}$ before the fall for 17 (11.3\%). The most commonly prescribed drugs during all time periods (i.e., within $24 \mathrm{~h}$ or 7 days before the fall or since the patient's admission) were lorazepam and zopiclone. The pharmacy database did not track administration of medications, so it is possible that some of the drugs prescribed were not actually taken by the patient.

Conclusion: Almost all inpatients who experienced a fall during the hospital stay had a prescription for at least one medication associated with a high risk for falls. Lorazepam and zopiclone were the drugs most commonly associated with falls in this hospital, and their use should be reviewed.

Key words: accidental falls, pharmaceutical preparations, inpatients

Can J Hosp Pharm 2011;64(5):321-326

\section{RÉSUMÉ}

Contexte : Bien que la cause des chutes soit multifactorielle, les médicaments en sont un facteur de risque clé pouvant être modifié. Les chutes sont l'un des événements les plus fréquents saisis dans le système d'identification des risques à l'hôpital des auteurs.

Objectifs : Déterminer si les patients hospitalisés en médecine générale qui ont subi une chute prenaient des médicaments reconnus pour être associés aux chutes.

Méthodes : On a effectué une revue de la littérature pour établir une liste des médicaments à haut risque associés aux chutes. Une étude rétrospective fondée sur une base de données visant l'amélioration de la qualité a fusionné les données tirées du système d'identification des risques aux données issues du système de distribution de la pharmacie portant sur les patients hospitalisés en médecine générale ayant subi une chute. Le paramètre d'évaluation principal était le pourcentage de patients ayant subi une chute constatée à qui l'on avait prescrit un médicament à haut risque. Le nombre de médicaments à haut risque ayant été prescrits aux patients qui avaient subi une chute a également été calculé.

Résultats : On a dénombré 82 médicaments différents associés à des chutes. Durant la période de l'étude (du $1^{\text {er }}$ avril 2008 au 31 mars 2009), 151 patients ont subi une chute. De ceux-ci, 144 (95,4\%) prenaient au moins un médicament à haut risque. Le nombre moyen de médicaments à haut risque par patient ayant subi une chute était de 2,2. De tous les cas de chutes consignés, on avait commencé à administrer un nouveau médicament à haut risque dans les sept jours précédant la chute chez 74 (49,0\%) des patients et dans les 24 heures avant la survenue de la chute chez 17 (11,3\%) des patients. Les médicaments les plus souvent prescrits pour toutes les périodes de temps (c.-à-d. moins de 24 heures ou de sept jours avant la chute ou depuis l'admission du patient) étaient le lorazépam et la zopiclone. La base de données de la pharmacie ne permet pas de savoir si les médicaments ont été réellement administrés et il est donc possible que certains des médicaments prescrits n'aient pas été pris par quelques patients.

Conclusion : Presque tous les patients ayant subi une chute durant leur hospitalisation avaient reçu une ordonnance d'au moins un des médicaments associés à un risque élevé de chute. Le lorazépam et la zopiclone étaient les médicaments les plus souvent associés à des chutes dans cet hôpital et leur utilisation devrait donc être examinée.

Mots clés : chutes accidentelles, préparations pharmaceutiques, patients hospitalisés

[Traduction par l'éditeur] 


\section{INTRODUCTION}

A fall is a sudden, unintended change in position causing an individual to land on a lower level. ${ }^{1}$ In the United States, a total of 10300 fatal fall injuries occurred in 2000, and they incurred an estimated total cost of US $\$ 179$ million. ${ }^{2}$ In the same year, an estimated 2.6 million nonfatal fall injuries resulted in a total cost of US\$19 billion. ${ }^{2}$ Although falls are often multifactorial, the risk of falls can be lessened by addressing any factors that are modifiable. Because falling is a common adverse event related to medications, ${ }^{3,4}$ modification of a patient's medication regimen is one possible method of reducing the risk of falls.

At the Red Deer Regional Hospital Centre, a nonteaching referral hospital (with about 400 beds) in rural Alberta, falls constituted the second most common event recorded in the risk identification system. The risk identification system was available at all computer terminals in the hospital, and any event that might cause patient harm could be entered into this system by any employee. From April 1, 2008, to March 31, 2009, a total of 287 falls were recorded in the system. Of these falls, 173 (60.3\%) occurred on 3 general medicine inpatient units.

Given the high costs associated with falls and the frequency of falls that occur in the hospital setting, this study was performed to identify whether general medicine inpatients who had experienced a fall were taking any medications known to be associated with falls.

\section{METHODS}

\section{Literature Search}

Two individuals (including M.Y.) independently conducted a comprehensive search of Ovid MEDLINE (1950 to May Week 3, 2009) to identify high-risk medications that have been statistically significantly associated with falling. The search strategy was based on the Medical Subject Headings (MeSH) "accidental falls" and "pharmaceutical preparations" combined with the keywords "falls", "medications", and "drugs". Articles retrieved were limited to studies in adults over 18 years of age with publication in English. One of the authors (M.Y.) screened the articles by reading the abstracts; when there was any doubt about suitability for inclusion, the full text was retrieved. Studies were included if the primary end point was identification of a statistically significant relation between the medication and an increased risk of falls. Studies were excluded if they specifically examined the adverse effects of a single medication. The medications identified through this literature search were then divided into categories created by the author team, as outlined in Table 1. High-risk medications associated with falling were defined as medications falling into categories $A$ and $B$ in Table 1. For situations in which only a class of medications was identified in the literature, a list of possible medications in that class was determined from the British National Formulary ${ }^{5}$ and the World Health Organization classification. ${ }^{6}$ These classes were then limited to products available in Canada.

\section{Inclusion and Exclusion Criteria for Patients with a Fall}

All patients for whom a fall had been entered into the risk identification system from April 1, 2008, to March 31, 2009 , were eligible for inclusion in the study. Because of time constraints, the review was limited to patients whose falls occurred on the 3 units of the hospital with the highest frequency of falls. These data were cross-referenced with the pharmacy database of medications ordered and dispensed for each patient by matching on the basis of the patient's name and date of birth. For patients with multiple hospital stays, the correct visit was selected by matching the appropriate admission and discharge date with the date of the fall as recorded in the risk identification system. Patients who were still in hospital at the time the analysis was conducted (in July 2009), those who had been admitted to the hospital for less than $48 \mathrm{~h}$, outpatients, and patients under 18 years of age were excluded.

\section{Data Analysis and End Points}

The risk identification system was used to identify all patients who fell between April 1, 2008, and March 31, 2009. The severity of injury, as determined by the individual who entered data about the fall, was also recorded. The severity of injury was categorized as follows: level 0 = near miss ("a situation that may potentially result in an incident or harm", as defined in the risk identification system), level 1 = an incident

\section{Table 1. Categories of High-Risk Medications}

\begin{tabular}{ll} 
Category & \multicolumn{1}{c}{ Definition } \\
\hline A & $\begin{array}{l}\text { Medication(s) or medication class reported as significantly associated with } \\
\text { an increased risk of falls in a meta-analysis, systematic review, or more than } \\
2 \text { unique observational studies }\end{array}$ \\
\hline B & $\begin{array}{l}\text { Medication(s) or medication class reported as significantly associated with } \\
\text { an increased risk of falls in only } 2 \text { observational studies }\end{array}$ \\
\hline C & $\begin{array}{l}\text { Medication(s) or medication class reported as significantly associated with } \\
\text { an increased risk of falls in only } 1 \text { observational study }\end{array}$ \\
\hline
\end{tabular}


with no adverse outcomes, level $2=$ an incident with minor adverse outcomes (i.e., patient experienced minor harm requiring minor treatment, additional monitoring, and follow-up), level $3=$ an incident with moderate adverse outcomes (i.e., patient sustained harm that was reversible by clinical interventions and that was anticipated to last less than 6 months), level $4=$ an incident with a serious or major adverse outcome (i.e., patient sustained harm that was not immediately reversible by clinical interventions and that resulted in a disability anticipated to last more than 6 months), and level 5 = an incident that resulted in death. A fall was considered to have associated morbidity if the person entering the information into the risk information system classified the severity as level 2 or higher.

For each fall in the risk identification system, all high-risk medications for which the patient had a prescription were recorded and categorized in relation to 3 time periods: new medications that had been prescribed in hospital in the 24-h period before the fall, new medications prescribed in hospital in the 7-day period before the fall, and any medications that had been prescribed for the patient since admission. No analysis was performed for discontinued medications and their potential relation to falls. For patients with prescriptions for more than one high-risk medication, each medication was analyzed separately in terms of time since initiation.

During data collection, no patient identifiers were retained, and all data were analyzed as aggregates. The primary end point of the study was the percentage of falls in which the patient had a prescription for one or more high-risk medications associated with falls, for each of the 3 prespecified time frames. Other end points were a comparison of the number of falls associated with single versus multiple high-risk medications; identification and ranking of medications according to which were most commonly prescribed for patients who fell; determination of average length of stay before the time of the fall; and determination of the number of falls with no injury, any injury, or death.

\section{RESULTS}

The literature search yielded 16 unique articles, consisting of 2 meta-analyses, ${ }^{7,8} 2$ systematic reviews, ${ }^{9,10}$ and 12 observational or retrospective studies. ${ }^{11-22}$ As anticipated, most of the articles identified classes of medications, not individual drugs. A list of 81 unique medications associated with increased risk of a fall was extrapolated from the published information, as presented in Table 2. This list of medications was used in reviewing the medication profiles of patients who experienced a fall.

Over the 1-year study period, the 3 patient care units with the most falls accounted for $173(60.3 \%)$ of all documented falls. These 3 units were all general medicine inpatient areas. As mentioned earlier, because of time constraints, data collection was limited to this sample of falls. Of the 173 falls, 10 were excluded from analysis because the patients had been admitted to hospital for less than $48 \mathrm{~h}, 8$ falls were excluded because

\section{Table 2. Medications Classified as High Risk}

\section{Medication Class}

Benzodiazepines?

Hypnotics, sedatives, and anxiolytics , $9-11,14,15,17,22^{2}$

Antidepressants $7,9,10,12,15-19,21,22$

\section{Medications}

Alprazolam, bromazepam, chlordiazepoxide, clobazam, clonazepam, clorazepate, diazepam, flurazepam, lorazepam, midazolam, nitrazepam, oxazepam, temazepam, triazolam

Barbiturates: pentobarbital, thiopental, phenobarbital, primidone

Aldehydes: paraldehyde

Other: buspirone, chloral hydrate, hydroxyzine, meprobamate, scopolamine, valerian, zopiclone

Tricyclic antidepressants: amitriptyline, clomipramine, desipramine, doxepin, imipramine, nortriptyline, trazodone, trimipramine

Selective serotonin reuptake inhibitors: citalopram, escitalopram, fluoxetine, fluvoxamine, paroxetine, sertraline

Monoamine oxidase inhibitors: maprotiline, moclobemide, phenelzine, quinupramine, tranylcypromine

Other antidepressants: bupropion, desvenlafaxine, duloxetine, mirtazapine, tryptophan, venlafaxine

Antipsychotics and neuroleptics $7,13,14,16,18-20,22$
Phenothiazines: chlorpromazine, fluphenazine, methotrimeprazine, perphenazine, pipotiazine, prochlorperazine, thioproperazine, trifluoperazine

Butyrophenones: droperidol, haloperidol

Diphenylbutylpiperidine: pimozide

Thioxanthenes: flupenthixol, zuclopenthixol

Atypical antipsychotic drugs: clozapine, olanzapine, quetiapine, risperidone

Indole derivative: ziprasidone

Other: lithium, loxapine, paliperidone

\begin{tabular}{ll}
\hline Antiepileptics ${ }^{9,21}$ & Phenytoin, carbamazepine \\
\hline Cardiac medications $^{8,14}$ & Thiazide diuretics: hydrochlorothiazide, mebutizide, trichlormethiazide \\
& Furosemide \\
& Type la antiarrhythmics: procainamide, quinidine \\
& Other: digoxin
\end{tabular}


there was no patient match between the risk identification system and the pharmacy database, and 4 falls were excluded because they involved patients who were still in hospital at the time the analysis was conducted. Therefore, 151 falls were included in the analysis. The patients included in the review experienced their falls between 2 and 178 days after admission, with a mean length of stay between admission and the fall of 25.5 days. The mean age of patients who had a fall was 73.5 years, and almost equal numbers of men and women had falls (Table 3).

The percentages of patients with prescriptions for one or more high-risk medications who had a fall are shown in Figure 1. Nearly all patients who fell (144 or $95.4 \%$ ) had a prescription for at least one high-risk medication, and most patients who fell had prescriptions for more than one high-risk medication (mean number of high-risk medications per patient 2.2 [Table 3]). The number of high-risk medications prescribed differed with the time interval analyzed: the shorter the time frame before the fall, the greater the chance that a single high-risk medication had been started during that time frame (Figure 1).

Regardless of the time frame, the most common medications prescribed to patients who fell were lorazepam and zopiclone. When the high-risk medications were grouped into classes, as in Table 4, benzodiazepines were the medications most commonly prescribed before a fall. Antipsychotics constituted the second most common class of medications prescribed before a fall for all time periods, despite the fact that only one antipsychotic (haloperidol) ranked among the top 5 medications prescribed before a fall.

Of the 151 falls analyzed, 91 (60.3\%) resulted in no injury, and $60(39.7 \%)$ resulted in an injury with severity of at least level 2. No falls resulted in death, according to the information recorded in the risk identification system.

\section{DISCUSSION}

Even with the strict criteria established for "high-risk" medications in this study, there were many classes of medications associated with falling. The large number of medications
Table 3. Demographic Characteristics of Patients Who Fell

\begin{tabular}{lc} 
Characteristic & $\begin{array}{c}\text { No. (\%) of Patients } \\
\text { or Mean (Range) }\end{array}$ \\
\hline No. of falls & 151 \\
Age, years & $73.5(25-95)$ \\
Sex, no. (\%) male & $78(51.7 \%)$ \\
\hline High-risk medications & \\
$\geq 1$ & $144(95.4 \%)$ \\
$\geq 2$ & $102(67.6 \%)$ \\
\hline Time to fall (days) & $25.5(2-178)$ \\
Mean & 14 \\
Median & 2.2 \\
\hline Mean no. of high-risk medications & 0.8 \\
Since admission & 0.1 \\
Started within 7 days before fall & \\
Started within 24 h before fall &
\end{tabular}

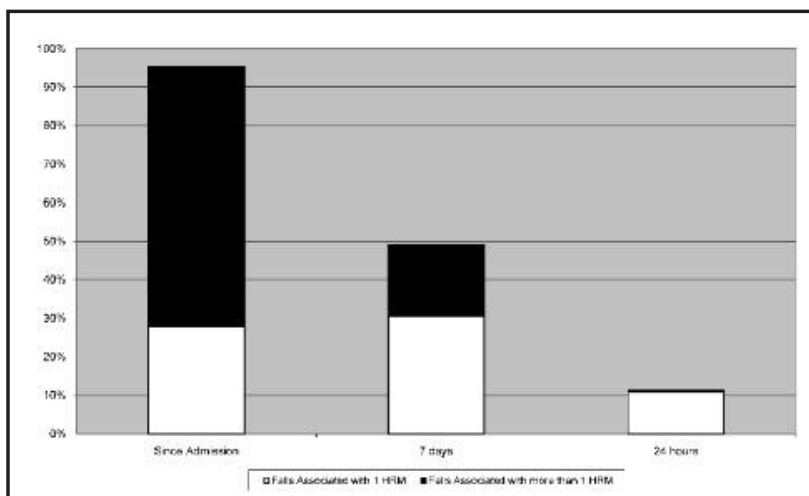

Figure 1. Occurrence of falls in relation to high-risk medications (HRMs). Data in the figure represent patients for whom at least one high-risk medication had been initiated in the specified time frames.

presents a challenge to practitioners, as it may difficult to recall such a lengthy list in day-to-day clinical practice. When we extrapolated a list of available medications from the classes of medications identified, the list consisted of 81 unique medications. What is not known at present is whether each medication in each class carries a risk of falling, or if certain medications

Table 4. Medication Classes Most Often Prescribed among Patients Who Had a Fall*

\begin{tabular}{lccc} 
& \multicolumn{3}{c}{ Time Frame of Initiation of Drug; No. (\%) of Fallst } \\
\cline { 2 - 4 } Medication Class & $\mathbf{2 4} \mathbf{~}$ Before Fall & 7 Days Before Fall & Since Admission \\
\hline Benzodiazepines & $6(4.0)$ & $28(18.5)$ & $83(55.0)$ \\
Antipsychotics & $5(3.3)$ & $23(15.2)$ & $65(43.0)$ \\
Hypnotics & $3(2.0)$ & $19(12.6)$ & $58(38.4)$ \\
Diuretics & $2(1.3)$ & $14(9.3)$ & $47(31.1)$ \\
SSRls & $2(1.3)$ & $17(11.3)$ & $42(27.8)$ \\
\hline
\end{tabular}

$\mathrm{SSRI}=$ selective serotonin reputable inhibitor.

*Some patients were receiving drugs from more than 1 class of high-risk medications at the time of the fall. tFor analysis of 151 falls over a 1 -year period. 
within a class are more likely to be associated with a fall. Although medications within a class may have different pharmacokinetics, their pharmacodynamics are generally similar. This similarity makes it plausible that all medications within a class would carry a similar risk for falls; however, we recognize that some medications may be more likely to be associated with falls than others. It is possible that applying a different method to identify high-risk medications might have yielded medications that were not included in our analysis but that might have an even stronger association with falls. Although the number of medications that may contribute to a fall is large, practitioners need to be able to recognize medications associated with falls when they are completing a patient's medication review upon admission to an acute care institution, so that interventions may be undertaken to lessen the chance of patients falling.

These data show that almost all patients who experienced a fall had a prescription for at least one high-risk medication. Only $49.0 \%$ of falls were associated with prescription of a new high-risk medication within the preceding 7 days, and many of the high-risk medications were prescribed on admission. Many medications prescribed at the time of admission are simply continuations of the patient's home medications, but it cannot be assumed that these medications are safe for the patient during a hospital stay. By virtue of their admission to an acute care institution, it is reasonable to assume that many patients will experience a change in pharmacokinetic parameters. In acute illness, there may be changes in absorption (e.g. decreased perfusion at the site of absorption or motility dysfunction), distribution (e.g., $\mathrm{pH}$ changes, fluid shifts, or changes in plasma protein binding), metabolism (e.g., disruption to hepatic blood flow), and excretion (e.g., decreased renal function). ${ }^{23}$ In addition, the disease state or disease states for which the patient is admitted may also be associated with an increased risk of falling. Although causality between medications prescribed and occurrence of falls cannot be determined from the analysis reported here, it appears that reviewing patients' medication regimens with the goal of reducing the use of medications associated with falling may be beneficial. Given that the majority of patients who fell were taking more than one high-risk medication, there is a possibility of undertaking several interventions to decrease the chance of a fall. The literature does not support the notion of an increased risk of falling with more than one high-risk medication, but expert opinion suggests that unnecessary medications be removed from the patient's regimen and that the lowest possible effective dose be used for those medications that are deemed necessary. ${ }^{24}$

In this sample of falls, almost all occurred in patients with a prescription for a high-risk medication, lorazepam and zopiclone being the individual drugs associated with the greatest number of falls. Given that zopiclone is indicated only for the treatment of insomnia ${ }^{25}$ and given that a common use of lorazepam is for nighttime sedation, it is possible that a number of falls may have been linked to the use of medications for this indication. Further research toward a safer procedure for nighttime sedation is warranted and may result in fewer falls.

Overall, harm was documented for about $40 \%$ of the falls, but this may be an underestimation. The severity of each fall was determined by the user of the risk identification system. It is possible that some people had injuries affecting their prognosis or leading to a longer length of stay that were missed by the reporter at the time of the incident report. The extent of such morbidity was not available from the database used. However, this possibility does suggest that actions to reduce the occurrence of falls are needed.

Many of the studies identified in the literature search involved geriatric patients, and it is uncertain whether their conclusions can be extended to the general population. However, in the present study, the mean age of patients experiencing falls was 73.5 years; as such, we believe that the method used to determine the list of high-risk medications was appropriate for the patient population studied. Another limitation of this analysis was that both aspects of data extraction (identification of high-risk medications from the literature and determination of use of high-risk medications by patients who fell) was done by a single reviewer (M.Y.). This drawback was lessened by having a librarian complete an independent literature review and provide relevant sources to the main reviewer.

The prescription data were extracted from a pharmacy database and not a computerized medication administration record. It is therefore possible that some patients were not taking the high-risk medications that had been prescribed for them. In this regard, medications that are prescribed for use on an as-needed basis are most likely to affect the results. Consequently, the data are presented as high-risk medications prescribed before a fall, and we acknowledge that some patients who had a fall may not have received all of the medications prescribed. Ideally, the timing of medication doses in relation to the fall would have been assessed for any potential correlation.

Although the reporting of incidents and near misses in the risk identification system is supported by the hospital's administration, it is possible that this system did not capture all of the events that occurred within the time frame of the study and that more falls occurred than were documented.

\section{CONCLUSIONS}

Many medications have been associated with falls, as documented in the literature, and nearly every patient who experienced a fall in 3 general medicine inpatient units in the study hospital had a prescription for at least one of these medications. Given that many such falls could cause some 
degree of morbidity, a review of patients' medications, to assess the risk of falling, is needed as part of a multidisciplinary fall prevention strategy. The best time for a medication review cannot be identified from this study. However, because many of the high-risk medications associated with falls appear to be started at the time of admission, this may be a reasonable time to review medications with the specific goal of decreasing the number of medications with a documented association with falling. Medications for nighttime sedation appear to be the most frequently prescribed medications before a fall, and a review of nighttime sedation procedures should also be undertaken.

\section{References}

1. Roth MT. Falls prevention. In: Pharmacotherapy self-assessment program. 5th ed. Kansas City (MO): American College of Clinical Pharmacy; 2004.

2. Stevens JA, Corso PS, Finkelstein EA, Miller TR. The costs of fatal and non-fatal falls among older adults. Inj Prev 2006;12(5):290-295.

3. Tinetti ME. Clinical practice. Preventing falls in elderly persons. $N$ EnglJ Med 2003;348(1):42-49.

4. Tinetti ME, Baker DI, McAvay G, Claus EB, Garrett P, Gottschalk M, et al. A multifactorial intervention to reduce the risk of falling among elderly people living in the community. $N$ Engl J Med 1994;331(13):821-827.

5. Joint Formulary Committee. British national formulary. 57 th ed. London (UK): BMJ Group and Pharmaceutical Press; 2009.

6. ATC/DDD index 2009. Oslo (Norway): WHO Collaborating Centre for Drug Statistics Methodology; 2009 [cited 2009 Jun 15]. Available from: www.whocc.no/atcddd/

7. Leipzig RM, Cumming RG, Tinetti ME. Drugs and falls in older people: a systematic review and meta-analysis: I. Psychotropic drugs. J Am Geriatr Soc 1999;47(1):30-39.

8. Leipzig RM, Cumming RG, Tinetti ME. Drugs and falls in older people: a systematic review and meta-analysis: II. Cardiac and analgesic drugs. J Am Geriatr Soc 1999;47(1):40-50.

9. Allain H, Bentué-Ferrer D, Polard E, Akwa Y, Patat A. Postural instability and consequent falls and hip fractures associated with use of hypnotics in the elderly: a comparative review. Drugs Aging 2005;22(9):749-765.

10. Sterke CS, Verhagen AP, van Beeck EF, van der Cammen TJ. The influence of drug use on fall incidents among nursing home residents: a systematic review. Int Psychogeriatr 2008;20(5):890-910.

11. Tanaka M, Suemaru K, Ikegawa Y, Tabuchi N, Araki H. Relationship between the risk of falling and drugs in an academic hospital. Yakugaku Zasshi 2008;128(9):1355-1361.

12. Lord SR, Anstey KJ, Williams P, Ward JA. Psychoactive medication use, sensori-motor function and falls in older women. Br J Clin Pharmacol 1995;39(3):227-234.

13. Neutel CI, Perry S, Maxwell C. Medication use and risk of falls. Pharmacoepidemiol Drug Saf 2002;11(2):97-104.

14. Rozenfeld S, Camacho LA, Veras P. Medication as a risk factor for falls in older women in Brazil. Rev Panam Salud Publica 2003;13(6):369-375.
15. Lawlor DA, Patel R, Ebrahim S. Association between falls in elderly women and chronic diseases and drug use: cross sectional study. BMJ 2003;327(7417):712-717

16. Mendelson WB. The use of sedative/hypnotic medication and its correlation with falling down in the hospital. Sleep 1996;19(9):698-701.

17. Souchet E, Lapeyre-Mestre M, Montastruc JL. Drug related falls: a study in the French Pharmacovigilance database. Pharmacoepidemiol Drug Saf 2005;14(1):11-16.

18. Hien le TT, Cumming RG, Cameron ID, Chen JS, Lord SR, March LM, et al. Atypical antipsychotic medications and risk of falls in residents of aged care facilities. J Am Geriatr Soc 2005;53(8):1290-1295.

19. Hanlon JT, Boudreau RM, Roumani YF, Newman AB, Ruby SM, Wright RM, et al. Number and dosage of central nervous system medications on recurrent falls in community elders: the Health, Aging and Body Composition study. J Gerontol A Biol Sci Med Sci 2009;64(4):492-498.

20. Formiga F, Navarro M, Duaso E, Chivite D, Ruiz D, Perez-Castejon JM, et al. Factors associated with hip fracture-related falls among patients with a history of recurrent falling. Bone 2008;43(5):941-944.

21. Angalakuditi MV, Gomes J, Coley KC. Impact of drug use and comorbidities on in-hospital falls in patients with chronic kidney disease. Ann Pharmacother 2007;41(10):1638-1643.

22. Thapa PB, Brockman KG, Gideon P, Fought RL, Ray WA. Injurious falls in nonambulatory nursing home residents: a comparative study of circumstances, incidence, and risk factors. J Am Geriatr Soc 1996; 44(3):273-278.

23. Boucher BA, Wood GC, Swanson JM. Pharmacokinetic changes in critical illness. Crit Care Clin 2006;22(2):255-271.

24. Tinetti ME, Kumar C. The patient who falls: "It's always a trade-off". $N$ Engl J Med 2010;303(3):258-266.

25. Imovane product monograph. Laval (QC): sanofi-aventis Canada Inc; 2010 July 2.

Richard P Cashin, BSc(Pharm), ACPR, PharmD, is a Clinical Practice Leader with Pharmacy Services, Alberta Health Services, Red Deer, Alberta.

Meiti Yang, BSC, is a Student Pharmacist and candidate for a BScPharm degree from the Faculty of Pharmacy, University of Alberta, Edmonton, Alberta. She was employed as a Summer Student Pharmacist while this project was being conducted.

\section{Address correspondence to:}

Dr Richard Cashin

Pharmacy Department

Red Deer Regional Hospital

3942 - 50A Avenue

Red Deer AB T4N 4E7

e-mail: richard.cashin@albertahealthservices.ca

\section{Acknowledgements}

The authors thank lan Creurer and Jeremy Slobodan for their contribution to the study concept; Sylvia Simmons and Sandra Rowell for assistance with collection of data from the risk identification system; Marie Rodway, Harry Ewasiuk, and Geoff Norris for valuable advice; and Dallas Foulston for editing assistance. 